\title{
Fruits Bioactive Compounds Characterization from a New Food Product
}

\author{
Valentina Mariana RUS, Francisc Vasile DULF, Carmen SOCACIU, Oana Lelia \\ POP, Floricuța RANGA, Florinela FETEA, Dan Cristian VODNAR*
}

Department of Food Science, University of Agricultural Sciences and Veterinary Medicine, 3-5 Mănăştur St, 400372,

Cluj-Napoca, Romania; dan.vodnar@usamvcluj.ro (*correspondingauthor)

\begin{abstract}
The aim of this study was (I) to create a new product, smart bar type which can be consumed as protective food by adults and children (II) to characterize the bioactive compounds from the designed food. The bioactive compounds were identified from nuts, raw seeds of almonds, dry cranberries, dry plums and flax seeds. Secoisolariciresinol $(683 \mathrm{ppm})$ has been identified as a major compound in flax seeds. The vitamin C was quantified by HPLC in a concentration of $35.02 \mathrm{mg} \%$ in cranberries extract. The total phenolic content varied from 7.1 $\mathrm{mg} / \mathrm{g}$ for walnut to $71.8 \mathrm{mg} / \mathrm{g}$ for cranberries. In addition, the antioxidative capability of phenolic compounds was monitored and evaluated using a colored free radical 2,2-diphenyl-1-picrylhydrazyl (DPPH). Almond showed better results than walnut in the antioxidant capacity test. The results obtained in this study collect information that enables the use of nuts, raw seeds of almonds, dry cranberries, dry plums and flax seeds as raw material for the production of smart bar which may serve as a new product for food market.

Keywords: antioxidant activity, bioactive compounds, lignans, smart bar
\end{abstract}

\section{Introduction}

Diet is the foundation of our life, it representing a permanent acting factor that leads metabolic processes development, due to the fact that food is considered the source and regulator of exchanges processes. In this context, the role of food industy takes shape in sanogenesis, role that, at the moment, is amplified by the fact that individual organism is requested, more than ever, by the environmental pollution and numerous stressors (Åkesson et al., 2014).

It highlights, in this way, the complexity of the relationship between humans and food by the many ways within nutrition affects the human body: metabolism, heat and energy balance, homeostasis, cells activity and development, motor activity and the behavior immmunecompetence, etc. Results, so, that the imbalance between intake and biologically active compounds requirements of the body, causes profound changes that will influence the health anomalies of modern human bing. With previously presented conditions, it started to take sense the idea to create a kind of food that has to be rich in biologicaly active substances, in order to prevent metabolic diseases and especially for the groups of people with a predisposition to certain diseases (Treuhaft and Karpyn, 2010; Menrad 2003).

Functional foods can prevent the appearance and the installation of various diseases in the body; moreover it can improve some existing metabolic disorders. In addition, it is clear that today the population orientation is to consume: foodstuff containing compounds that promote health, such as: antioxidants, vitamins, calcium, magnesium, flavones, mono and polyunsaturated fatty acids, especially alphalinolenic acid, strengthening by this way the belief according to which "through a right attitude, including nutrition, you can prevent cancer" (Alzamora et al., 2005; Jones and Jew, 2007; Saarela et al., 2002). Development of functional foods involved incorporation of specific compounds (or ingredients) with demonstrated health effects (Hamer et al., 2005).

Another current direction in consumer perception is the awareness of a strong link between physic and mental condition and food, but also between diet, longevity and physical appearance and, accordingly, the belief that diet provides promising solutions for our health than the medical cabinet. Therefore, it can be notice a tendency in resorting to deseases prevention, excluding more and more the possibility of treating it (Goetzke et al., 2014).

In view of the previously exposed and given the fact that a functional food have to be a similar product, in appearance, to a conventional food (Siro et al., 2008), that has to be consumed as part of a regular diet and to contain active ingredients with proven physiological benefits, possesing, in addition, the potential to reduce the risk of a certain dissease and accomplishing, not least, nutritional functions, the aim of this study was (I) to create a new product, smart bar type that can be consumed like protective food by adults and by childrens and (II) to characterize the bioactive compounds from the designed functional food.

\section{Materials and methods}

\section{Plant material}

The walnutes, almonds, cranberrys and plums were purchased from local producers from Cluj county. The fruits were stored at refrigerated $\left(4^{\circ} \mathrm{C}\right)$ storage until the utilization. 
The walnuts and almonds were maintained at room temperature.

\section{Diagram of the smart bar production}

$50 \mathrm{~g}$ crushe dalmonds, $50 \mathrm{~g}$ walnuts, $50 \mathrm{~g}$ dried cranberries, $50 \mathrm{~g}$ plumsand $30 \mathrm{~g}$ flax seedswere mixed it together by homogenization. After homogenization $10 \mathrm{~g}$ of honey was added, then wasad ded $10 \mathrm{~g}$ of honey, for composition binding. In order to achieve a very well tight smart bar was used hot dissolved apple pectin in concentration of $4 \%$.

\section{Extraction method}

Each raw material $(2 \mathrm{~g})$ was homogenized with $10 \mathrm{ml}$ distilled water, or with $10 \mathrm{ml} 98 \%$ ethanol using an UltraTurax homogenizer, for $1 \mathrm{~min}$. This mixture was centrifuged (10 000 $\mathrm{rpm}$, at $4^{\circ} \mathrm{C}$, for $10 \mathrm{~min}$ ) and the supernatants were filtered through filter paper. The filtrate was used for the intended analysis.

Determination of antioxidant activity by 2,2-diphenyl-1picrylhydrazyl (DPPH) method

2,2-diphenil-1-picrilhidrazil method in its modified version is based on measuring the antioxidant complexing ability about thestable radical DPPH.DPPH • radical is one of the few stable nitrate radical, that has a purple colour and that when it is reduced by the antioxidant, it get fade/it discolors. The reaction is monitored by a spectrophotometer at a wavelenght of $515 \mathrm{~nm}$. The reaction was performed in 12 wellplate. A volume of $200 \mu \mathrm{l}$ sample and $1.4 \mathrm{ml} \mathrm{DPPH}$ solution $(80 \mu \mathrm{M})$ were added to each microplate well. The decrease in the absorbance of the resulting solution was monitored at 515 $\mathrm{nm}$ for $30 \mathrm{~min}$. The calibration curve was performed with Trolox, using various dilutions $(500 \mu \mathrm{M}, 250 \mu \mathrm{M}, 125 \mu \mathrm{M}$ to $3.95 \mu \mathrm{M})$. The equation curve was $\mathrm{y}=0.0029 \mathrm{X}+0.0108$ and $\mathrm{R}^{2}=0.9985$.

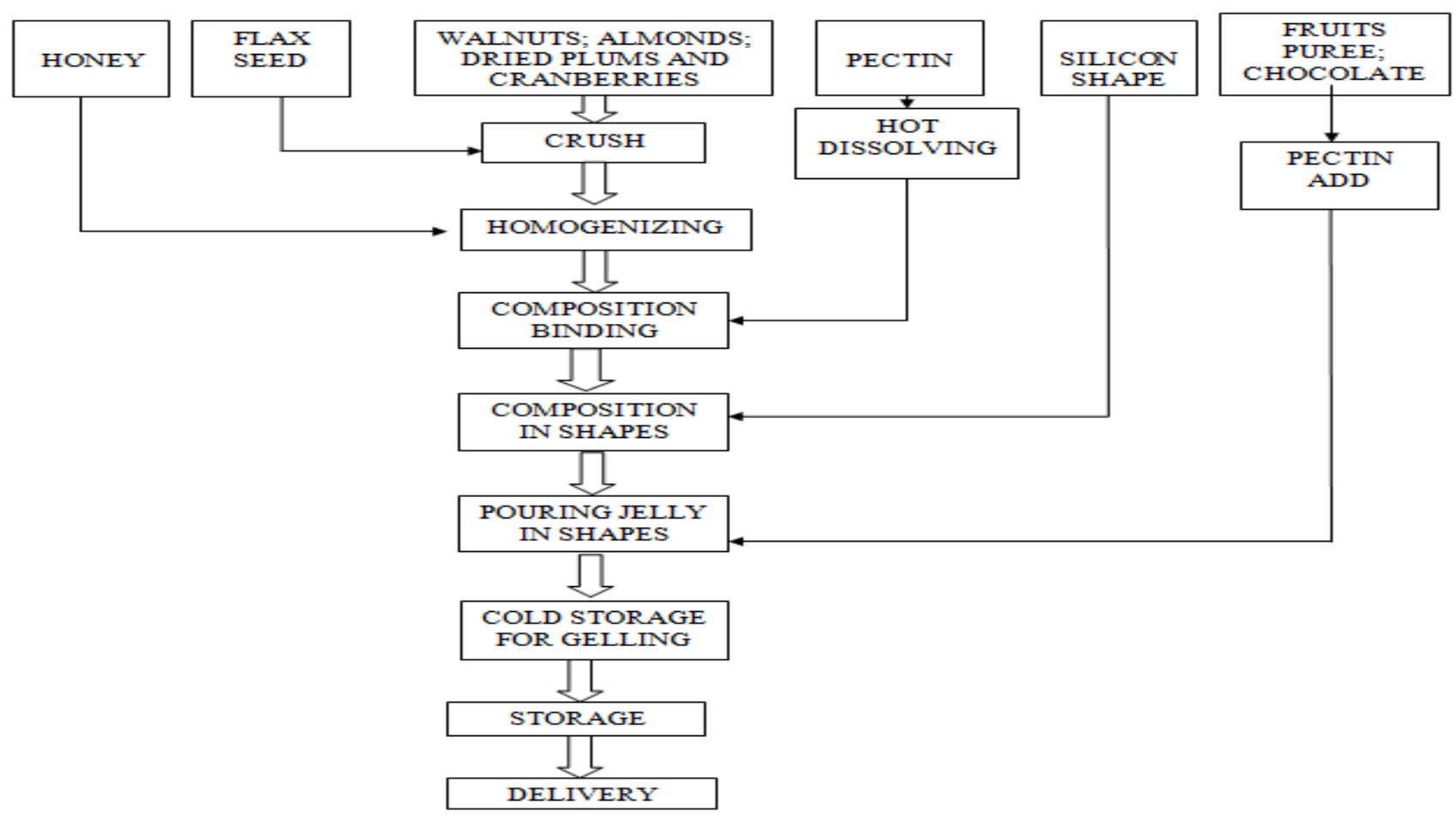

Total polyphenols determination by Folin Ciocalteu Method

Total phenolic content was determined by the FolinCiocalteu method. The extracts $(23 \mu \mathrm{l})$ were mixed with $1817 \mu \mathrm{l}$ distilled water, $115 \mu \mathrm{l}$ Folin-Ciocalteu reagent (dilution $1: 10, \mathrm{v} / \mathrm{v}$ ) and $345 \mu \mathrm{l}$ of $15 \% \mathrm{Na}_{2} \mathrm{CO}_{3}$ solution, and the mixture incubated at room temperature, in the dark, for 2 h. The absorbance was measured at $765 \mathrm{~nm}$ using a spectrophotometer. The calibration curve was linear for the range of concentrations between 0.1 to $0.5 \mathrm{mg} / \mathrm{ml}$ gallic acid. The results were expressed in $\mathrm{mg}$ gallic acid equivalents (GAE)/g fresh matter). The principle consists in determination of total polyphenols content of vegetal sources by measuring the optical density of a primary extract which, by Floin-Ciocalteu complexing, absorbs in the visible range at $750 \mathrm{~nm}$ wavelength. The total amount of polyphenols is expressed relative to a gallic acid calibration curve. The standard curve equation is: $\mathrm{y}=0.9443 \mathrm{X}+0.0608$ and $\mathrm{R}^{2}=$ 0.9945 .

Identification of ascorbic acid in cranberries by HPLC method

For the ascorbic acid separation, identification and determination was used an Agilent $1200 \mathrm{HPLC}$ system with UV-Vis detector. Separation was done on an Eclipse XDBC18 column size $150 \times 4,6 \mathrm{~mm}$ with $5 \mu \mathrm{m}$ particle size. The column was eluted under isocratic mobile phase system: water/acetonitile/ formic acid 94/5/1(v/v/v) with a flow rate of $0.5 \mathrm{ml} / \mathrm{min}$. The chromatograms were recorded at 240 $\mathrm{nm}$. For the identification and determination of ascorbic acid in the samples a standard of L-ascorbic acid, purity 99\%, was used.

\section{$U V$-VIS spectrum offlavonoids in plum fruits extract}

An aliquot of $25 \mathrm{~mL}$ of plum extract was diluted with 30 $\mathrm{mL}$ of $95 \%$ ethanol (v/v) to determine the absorption

Diagram of the smart bar production 
472

spectrum in theregion in the UV-V is region using Jasco 530 UV-VIS spectrophotometer.

Determination oflignans from flax seeds by HPLC method

Lignans by flax seeds sample were extracted in $1 \% \mathrm{HCl}$ acidified methanol. The extract was filtered through a 0.45 $\mu \mathrm{m}$ nylon filter and injected into the HPLC system (UV Agilent 1200 series). Chromatographic analysis was carried out using a Shimadzu HPLC system equipped with a UV-Vis DAD detector and a Zorbax C18 4.6x $150 \mathrm{~mm}, 5 \mu \mathrm{m}$. The mobile phases used $1 \%$ acetic acid in water (A) and methanol (B) and the flow rate was $1.2 \mathrm{ml} / \mathrm{min}$ at wavelength of 280 $\mathrm{nm}$. The analysis was performed using the following linear gradient of A-B: $0 \mathrm{~min}, 10: 90$; $40 \mathrm{~min}, 95: 5,45 \mathrm{~min}, 10: 90$ (total run time $55 \mathrm{~min}$ ).

\section{Results and discussions}

\section{Antioxidant activity}

The antioxidant activity of walnut and almond extracts equivalent factor ( $\mu \mathrm{M}$ Trolox) are shown in Tab. 1 . As can be observed from the table, both inhibition factors and the equivalent factor of Trolox, are relatively close for both extracts, mentioning that higher values, in both cases, are held by almonds. Some researchers argue that there is also a synergy between the flavonoids in the peel and vitamin $\mathrm{E}$ in the core, both components possessing, separately, antioxidant activity, an activity that is intensified when the two compounds work together and help each other (Matthes and Schmitz-Eiberger, 2009).

The total phenolic contents in the examined extracts using the Folin-Ciocalteu's reagent is expressed in terms of gallic acid equivalent (Tab. 2).

Tab. 1. Inhibition percent ( $\mathrm{I} \%$ ) and Trolox equivalent factor $(\mathrm{F})$ in $\mathrm{mM}$

\begin{tabular}{lcc}
\hline Sample name & $\mathrm{I} \%$ & $\mathrm{~F}(\mathrm{mM}$ Trolox/1ml extract $)$ \\
\hline Walnut & 6.9 & $7.36 \pm 0.1$ \\
Almond & 7.1 & $8.23 \pm 0.2$ \\
\hline
\end{tabular}

Tab. 2. Total polyphenols in walnut and cranberries samples

\begin{tabular}{lcc}
\hline \multicolumn{1}{c}{ Sample } & Gallic acid equivalents & Sample \\
\hline Walnut & $7.1 \pm 0.8(\mathrm{mg} / \mathrm{g})$ & Walnut \\
Cranberries & $71.8 \pm 1.6(\mathrm{mg} / \mathrm{g})$ & Cranberries \\
\hline
\end{tabular}

Based on the results presented in the Tab. 2 it can be easily observed that the cranberries had a bigger content in total polyphenols gallic acid equivalentrs than the walnut. Our results are in agreemnt with those reported by Borowska $e t$ al. (2009). Considering the results obtained in polyphenols determination and their potential action in the body, it must be appreciated their presence in walnuts and cranberries, particularly, and as a result, it is important to realize the need to include them in our daily diet.

\section{Ascorbic acid identification in cranberries by HPLC}

The retention time for the L-ascorbic acid chromatogram (Fig. 1) for cranberries extract was 3.2 minutes. Finally, by calculating the concentration of vitamin $\mathrm{C}$ in the sample, we obtained a value of $35.02 \mathrm{mg} \%$. The result is in agreement with those reported by Habash et al., 1999. Due to its multiple properties, biological and therapeutic, cranberries have been widely studied by many scientists. They concluded that, a very important attribute is the fact that the phytonutrients isolated from cranberries juice have not the same health benefits as taking the phytonutrients by the whole cranberries as a synergistically group (Reed, 2002).

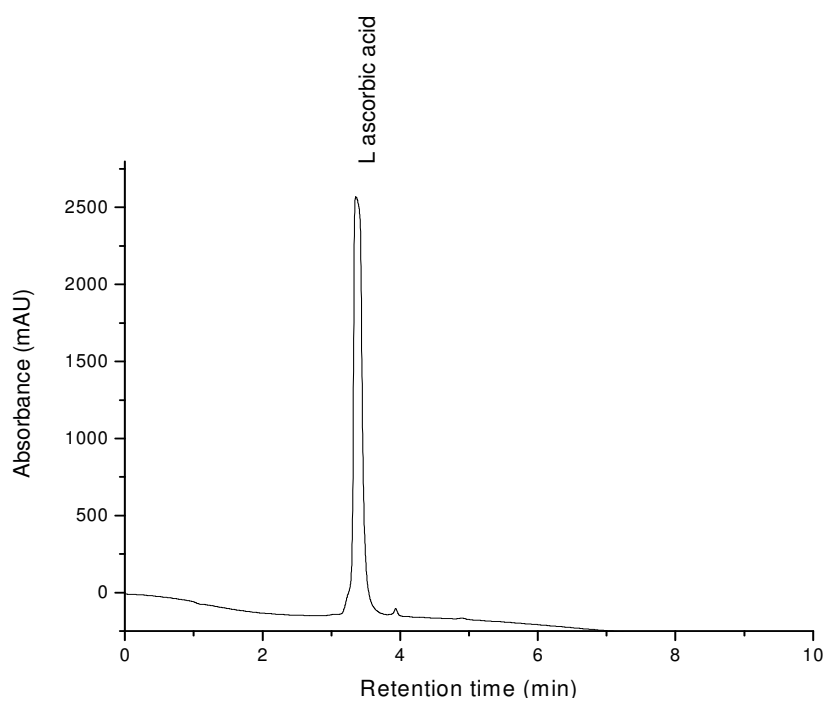

Fig. 1. Chromatogram of ascorbic acid (standard)

Determination of flavonoids in plum fruits extract-UV-VIS spectrum

Following the qualitative determination of flavonoids in plums extract, it was recorded, in the UV-VIS range, a characteristic spectrum of this type of phenolic compounds. The main property of phenolic compounds is its antioxidant capacity and, therefore, it's potential to fight against free radicals and chain reactions that all this might trigger. In Fig.2, it can be seen that there was recorded a $360 \mathrm{~nm}$ maximum absorption, this peak being associated with flavonoids: $\mathrm{DO}_{360}=0.24$. At $280 \mathrm{~nm}$ wavelength were identified phenolic acids: $\mathrm{DO}_{280}=0.41$.

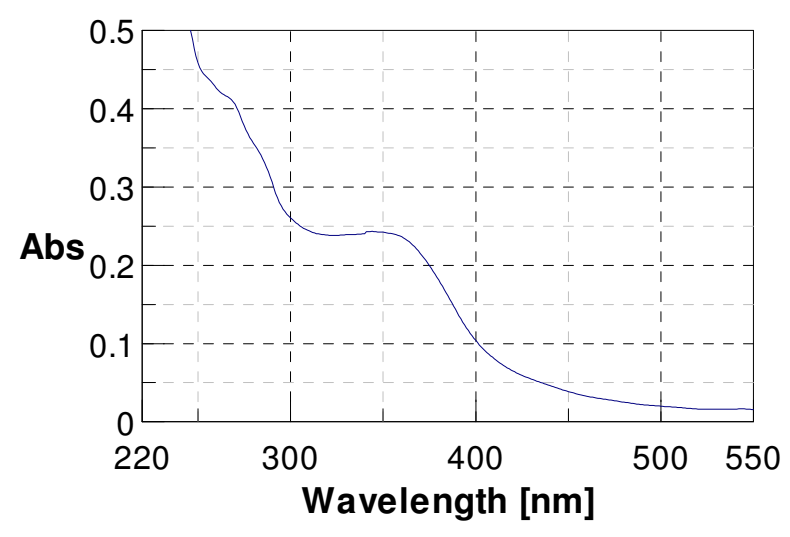

Fig. 2. UV-VIS spectrum for phenolic compounds in plums

Lignans detection from flax seeds by HPLC

For the flax seeds lignans determination it was used lignans standards. The recorded chromatogram in the lignans standards is shown in the Fig. 3.

The following determined were the seeds sample lignans, thus registering the chromatogram in Fig. 4 and, in this way, becoming possible a comparison between the two chromatograms. 


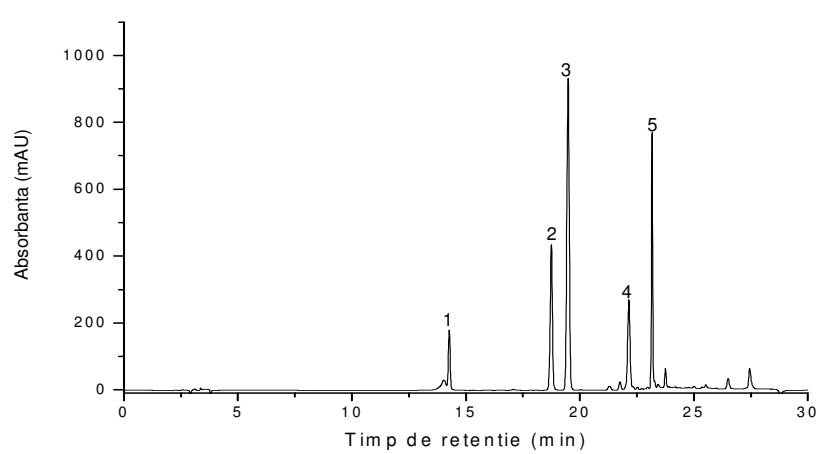

Fig. 3. Lignans standard chromatogram: 1-SDG; 2-SECO; 3LARI; 4-PINO; 5-MATA (for abbreviations see Tab. 3)

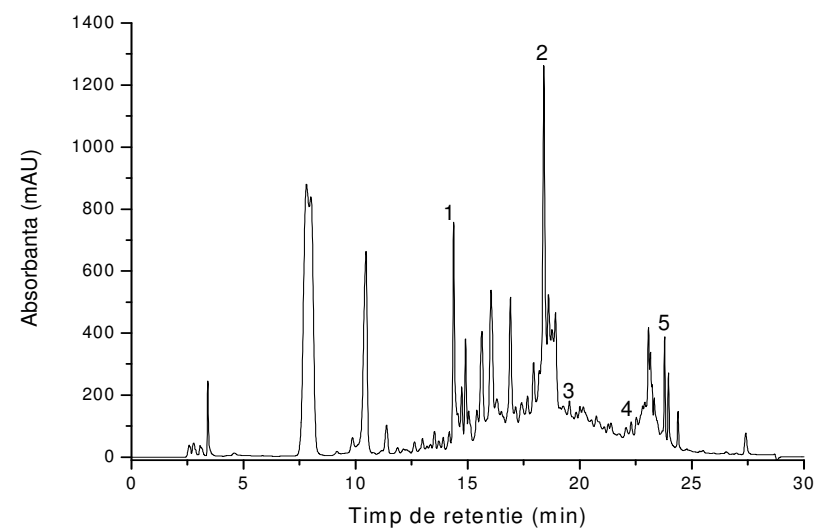

Fig. 4. Flax seeds sample chromatogram: 1-SDG; 2-SECO; 3-LARI; 4-PINO; 5-MATA (for abbreviations see Tab. 3)

Analyzing standards chromatograms of lignans and flax seed lignans in the sample, we can see that in the case of standard lignans, the largest peack is held by secoisolariciresinol (SECO), the last one recording an amount of $683.43 \mathrm{ppm}$ and a retention time of 18.7 minutes, as we can see it in the Tab. 3 .

Tab. 3. The lignans quantity in the seeds sample

\begin{tabular}{lcc}
\hline \multicolumn{1}{c}{ Lignan } & $\begin{array}{c}\text { Retention time } \\
\mathrm{tR}(\mathrm{min})\end{array}$ & $\begin{array}{c}\text { Lignan quantity } \\
(\mathrm{ppm})\end{array}$ \\
\hline Secoisolariciresinol diglucoside (SDG) & 14.3 & 274.55 \\
Secoisolariciresinol (SECO) & 18.7 & 683.43 \\
Lariciresinol (LARI) & 19.4 & 101.46 \\
Pinoresinol (PINO) & 22.1 & 31.747 \\
Matairesinol (MATA) & 23.8 & 110.09 \\
\hline
\end{tabular}

Flax seeds consumption (through intake lignans) brings essential benefits, due to its antioxidants and antiinflammatory. Those two components are cofactors, as we well know, in preventing the occurrence of various cancer types. This is due to the fact that chronic inflammation and chronic oxidative stress, it is representing risk factors on cancer development (Lin et al., 2002; Boccardo et al., 2004).

\section{Conclusion}

The importance of functional food products has been well recognized in connection with health promotion, disease reduction re duction, and reduction in health care costs. Bioactive compunds can be used as value added ingredients in the development of functional food products, particularizing their case by incorporating them into a smart bar. Therefore, sunch functional product (smart bar) may provie a means to achive desired health effects without the need for ingestion of dietary supplements, medications, or major cange in dietary habits.

\section{Acknowledgements}

This work was conducted through Partnerships in Priority Areas Programme-PN II, developed with the support of MEN-UEFISCDI Project No. 154 (PN-II-PTPCCA-2013-4-0743).

\section{References}

Åkesson A, Larsson SC, Discacciati A, Wolk A (2014). Lowrisk diet and lifestyle habits in theprimaryprevention of myocardialinfarction in men: A Population-Based Prospective CohortStudy. J Am CollCardiol 64(13):12991306.

Alzamora SM, Salvatori D, Tapia SM, Lopez-Malo A, WeltiChanes J, Fito P (2005). Novel functional foods from vegetable matrices impregnated with biologically active compounds. J FoodEng 67:205-214.

Boccardo F, Lunardi G, Guglielmini P, Parodi M, Murialdo R, Schettini G, Rubagotti A (2004). Serum enterolactone levels and the risk of breast cancer in woman with palpable cysts. Eur J Cancer 40:84-89.

Borowska EJ, Mazur B, Kopciuch RG, Buszewski B (2009). Polyphenols, Anthocyanins and Resveratrol in Cranberry. Food Technol Biotechnol 47(1):56-61.

Goetzke B, Nitzko S, Spiller A (2014).Consumption of organic and functional food. A matter of well-being and health? Appetite 77(1):96-105.

Habash MB, Van der Mei HC, Busscher HJ, Reid G (1999). The effect of water, ascorbic acid, and cranberry derived supplementation on human urine and uropathogen adhesion to silicone rubber. Can J Microbiol 45(8):691694.

Hamer M, Owen G, Kloek J (2005). The role of functional foods in the psychobiology of health and disease. NutrResRev 18(1):77-88.

Jones PJ, Jew S (2007). Functional food development: Concept to reality. Trends FoodSciTech 18:387-390.

Lin X, Gingrich JR, Bao W, Li J, Haroon ZA, Demark-Wahn W (2002). Effect of flaxseed supplementation on prostatic carci noma in transgenic mice. Urology 60:919-924.

Menrad K (2003). Market and marketing of functional food in Europe. J Food Eng 56:181-188.

Reed J (2002). Cranberry flavonoids, atherosclerosisand cardiovascular health. Crit Rev Food Sci Nutr 42:301-316.

Saarela M, Lahteenmaki L, Crittenden R, Salminen S, MattilaSandholm T (2002). Gut bacteria and health foods-The European perspective. Int J FoodMicrobiol 78:99-117.

Siro I, Kapolna E, Kapolna B, Lugasi A (2008). Functional food. Product development, marketing and consumer acceptance-A review. Appetite 51:456-467.

Treuhaft S, Karpyn A (2010). The grocery gap: Who has access tohealthy food and why it matters. http://thefoodtrust.org/uploads/media_items/grocerygap. original.pdf. 